\title{
Rash of Motorcycle Accidents: A Growing National Health Concern
}

\author{
Mario B. Geronilla ${ }^{1}$ and Joseph Keat T. Sison ${ }^{2}$ \\ ${ }^{1}$ Department of Orthopedics, College of Medicine and Philippine General Hospital, University of the Philippines Manila \\ ${ }^{2}$ Department of Orthopedics, East Avenue Medical Center, East Avenue, Quezon City
}

\begin{abstract}
Introduction. Discussions on road safety are both timely and relevant. From its sixth place place in 1995, death from road accidents rose to fourth in 2004, and is expected to become the second leading cause of death worldwide by 2020. It is notable that road accidents specifically motorcycle accidents are increasingly more common among developing countries such as the Philippines.
\end{abstract}

Objectives. Because of this growing public concern, this crosssectional descriptive study aims to determine the profile of motorcycle accidents in Metro Manila, the prevalence of musculoskeletal injuries resulting from such accidents, and to propose recommendations for its prevention.

Methods. Charts and clinical records of road accident victims from three major institutions namely, the Philippine General Hospital, Philippine Orthopedic Center and East Avenue Medical Center were selected. The profile of these patients and the incidence of musculoskeletal injuries were gathered.

Results. Males were found to be more involved in these accidents with an average age in the range of 21 to 35 years. The most common time of fatal vehicular accidents was at 9 p.m. while nonfatal injuries occurred most commonly around 4 a.m. Motorcycles rank as the leading cause of injuries to motorists, both fatal and nonfatal. There was a $16.3 \%$ increase in the incidence of motorcycle-related musculoskeletal injuries from 2007 to 2008. The lower extremity was involved in half of cases with the rest occurring in the spine and upper extremity. The most commonly involved segment was the tibia (25\%), followed by the femur (20\%) and the forearm (12.5\%).

Summary and Recommendations. It is apparent that the increase in vehicular crash causing fatal accidents is due to an increased number of motorcycles and cars, and these commonly involve the pedestrian and drivers. It is understandable that in order to improve road safety, education should be enhanced among motorists and students alike as a form of prevention, and primary trauma centers should be determined to facilitate identifying which centers can adequately manage these injured motorists.

Key Words: road safety, motorcycle accident, fatal injuries, nonfatal injuries, musculoskeletal injuries

Corresponding author: Mario B. Geronilla, MD

Department of Orthopedics

Philippine General Hospital

University of the Philippines Manila

Taft Avenue, Ermita, Manila 1000 Philippines

Telephone: +632 5548466

Email: dr_geronilla@yahoo.com

\section{Introduction}

Road accidents remain one of the top ten leading causes of death. In fact, it has gone up from being the sixth leading cause of mortality in 1995 to fourth in 2004 and is expected to become the second leading cause of death worldwide by 2020. ${ }^{1}$ The World Health Organization (WHO), realizing the increasing incidence of road accidents, declared the Decade of Action for Road Safety beginning 2011 to 2020 to address this growing concern. It is notable that road accidents, especially those involving motorcycles, are increasingly more common among developing countries such as the Philippines. $^{2}$ It is therefore imperative that more information be gathered concerning this growing health risk so that national health policy makers as well as other stakeholders may address this issue. This study is part of the initiative of the Philippine Orthopaedic Association (POA) which has launched a Road Safety Program. As an initial phase of this program, the profile of road traffic accidents involving motorcycles was gathered, hoping to get a better understanding of this problem.

\section{Objectives}

The general objective of this paper is to determine the profile of road traffic accidents resulting in musculoskeletal injuries based on the data obtained from three selected major hospitals.

The specific objectives are:

1) to establish the profile of road accidents in general and motorcycle accidents in particular

2) to determine the prevalence of musculoskeletal injuries and other selected injuries

3) to determine the factors related to increase in number of motorcycle accidents

4) to come up with national and comprehensive recommendation for the prevention of motorcycle accidents

\section{Methods}

A cross-sectional study was undertaken in three major hospitals. All patients who consulted the emergency room after a road accident were included in the study. The clinical records of road accident victims from the three major institutions, namely, the Philippine General Hospital, ${ }^{3}$ Philippine Orthopedic Center ${ }^{4}$ and East Avenue Medical Center ${ }^{5}$ were selected as pilot centers for study, because of 
their geographical location and their catchment areas. These three hospitals are referral centers for almost all of Metro Manila and the northern, southern and eastern provinces, cities and municipalities, which therefore represent the large urban and suburban areas very well. Additional data was obtained from the $\mathrm{LTO}^{6}$ and the Metro Manila Development Authority (MMDA), ${ }^{7}$ Metro Manila Traffic Accident Reporting and Analysis System (MMARAS) from 2005-2008 and the POA Trauma Registry. ${ }^{8}$ The data was analyzed to produce a broader report on the profile of traffic accidents and the prevalence of associated upper or lower extremity fractures, spine injuries and brachial plexus injury in Metro Manila and its suburbs. The data obtained represents a significant cross-sectional perspective relevant to this study.

\section{Results}

The results of this study are both enlightening and alarming, and indeed underscore the belief of the author that the rash of motorcycle accidents is a fast-growing national health concern which must be addressed with resoluteness and urgency.

The data from the three (3) pilot tertiary hospitals show that $(9.4 \%)$ of all emergency consults were due to vehicular crash. Male patients predominate at 2:1 ratio (male:female) (Figure 1). Almost half (42.2\%) of the victims of vehicular crash belong to the 21-35 age group (Figure 2). In the same data, motorcycle accident victims account for $2 / 3(62.2 \%)$ belonging to the same age group (Figure 3).

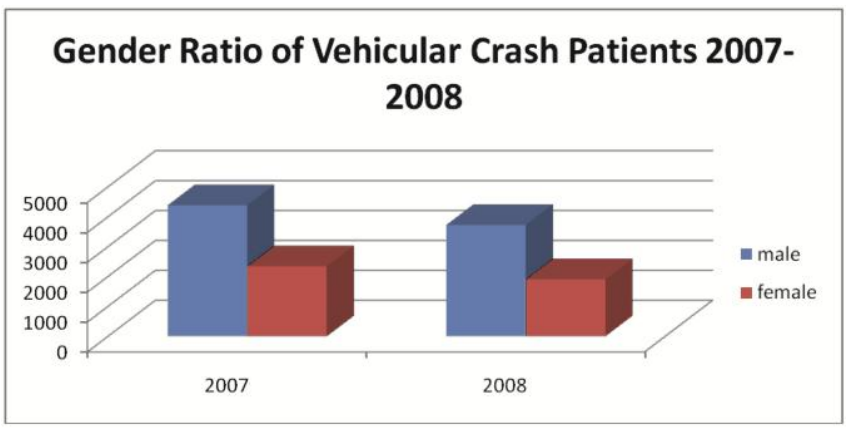

Figure 1. Gender breakdown of vehicular crash patients 2007-2008 (EAMC, PGH and POC Database).

Most vehicular accident fatalities are seen at 9 p.m., 2 a.m. and 6 a.m. in decreasing order (Figure 4). On the other hand, nonfatal accidents show an increasing trend from 4 a.m., peaking at 10 a.m. An abrupt drop is seen between 1 p.m. to 6 p.m. (Figure 5).

From the three hospitals, motorcycle accident had an increase in incidence of $16.3 \%$ in musculoskeletal injuries in 2008 compared to 2007. Almost half 875/2002 (44\%) were injuries to the lower extremities. Among all musculoskeletal injuries, the leg injuries have the highest percentage $(25 \%)$ followed by the femur (20\%) and forearm (12.5\%); of the joint injuries, knee injury accounts for (11\%), followed by wrist $(8.2 \%)$, hip $(2.7 \%)$, and ankle $(2.5 \%)$. Only $3.7 \%$ of motorcycle crash victims have spine injuries (Figure 6). This data was similar to the results of the review of POA Trauma Registry for the same period (2007-2010) $)^{8}$ (Table 1).

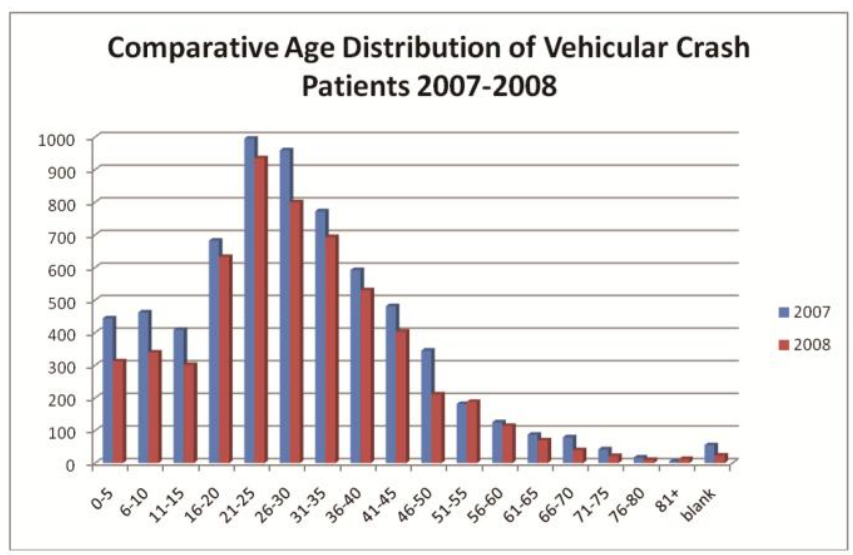

Figure 2. Age distribution of vehicular crash patients from 2007-2008 (EAMC, PGH and POC Database).

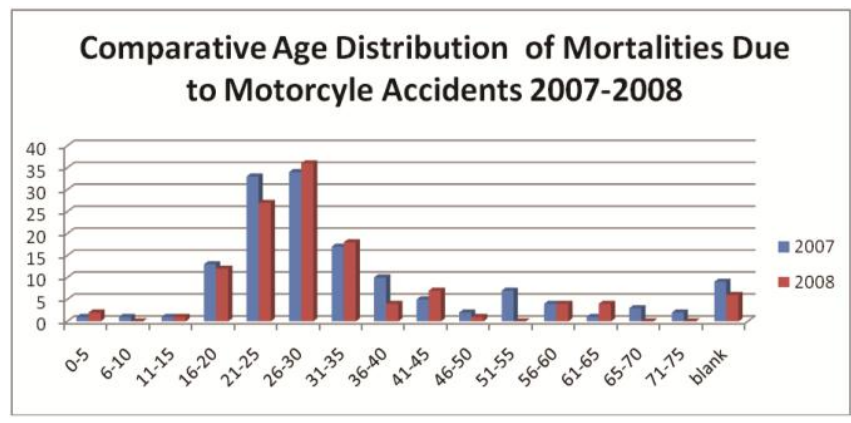

Figure 3. Age distribution of fatal motorcycle accidents from 2007-2008 (EAMC, PGH and POC Database).

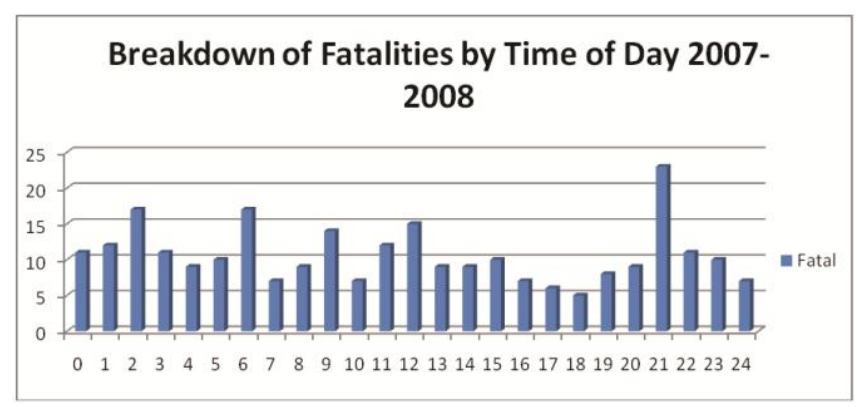

Figure 4. Breakdown of fatalities by time of day from 20072008 (EAMC, PGH and POC Database).

In a recent case series study ${ }^{9}$ on brachial plexus injuries seen at PGH, 78.6\% (22/28) was due to motorcycle accident; $54 \%$ of them were under the influence of alcohol at the time of injury. The rate was followed by other causes, e.g., fall, machine traction, and other vehicular accidents. 


\section{Breakdown of Nonfatal Injuries by Time of Day 2007-2008}

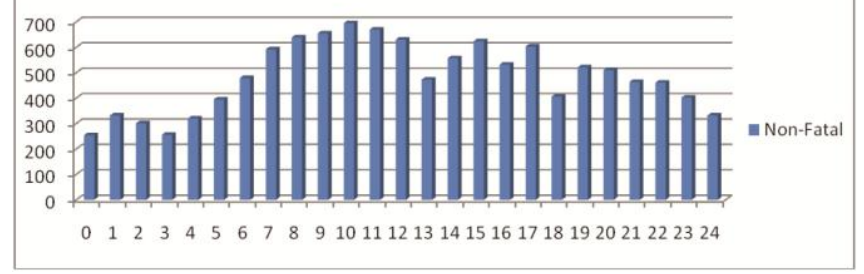

Figure 5. Breakdown of nonfatal motorcyle accidents by time of day from 2007-2008 (EAMC, PGH and POC Database).

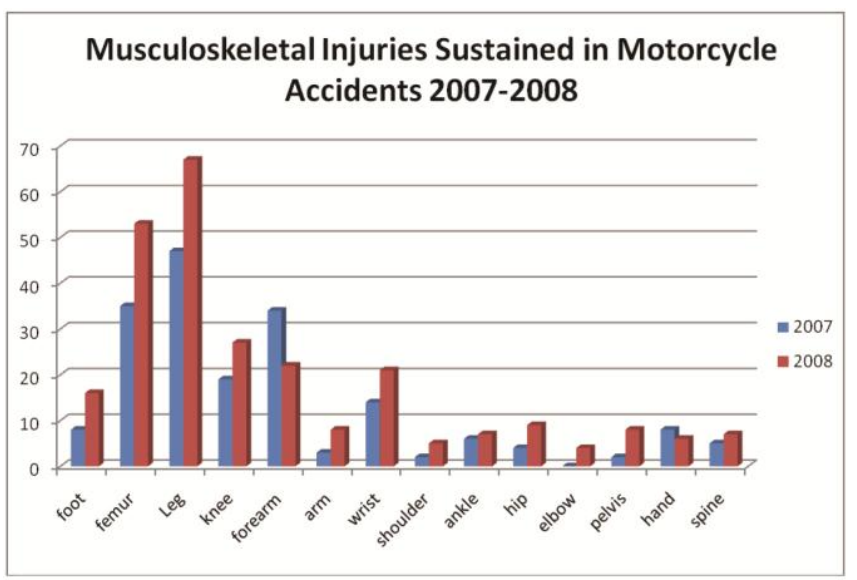

Figure 6. Musculoskeletal injuries sustained in motorcycle accidents from 2007-2008 (EAMC, PGH and POC Database).

In another study by Estrella, ${ }^{10}$ high-speed motorcycle vehicular accidents accounted for the majority of all traumatic brachial plexus injuries, the majority of these injuries due to motorcycle accidents which are seen to be steadily rising in developing countries. ${ }^{11}$

\section{Discussion}

Motorcycles have fast become the preferred vehicle of transport particularly in developing countries because they are relatively inexpensive to own, consume less fuel and are easily maneuverable especially in increasingly congested roadways. ${ }^{12}$ Furthermore, the acceleration to transit time is shorter compared with other automobiles. This trend was confirmed by our study in which motorcycles had an $11 \%$ annual increase in number of registered vehicles from 2005 to 2006. It is noted that there was an increase of about $40 \%$ in the previous four (4) years. ${ }^{13}$ As of 2008, there were 5,331,574 registered vehicles of which $50.9 \%$ are classified as motorcycles/tricycles; the remaining number was classified as utility vehicles $(24 \%)$, cars $(13 \%)$, trucks $(5 \%)$, SUVs $(3 \%)$, buses $(1 \%)$ and tractors $(1 \%)$ (Table 2). There is no foreseeable decline in this since the cost of acquiring a motorcycle is getting cheaper and the road conditions remain the same in our country. ${ }^{14}$ Considering this trend, it is important to note that $60 \%$ of registered vehicles will be motorcycles by 2010 (actual data not available at this writing).

Table 1. Common fractures in motorcycle accidents (Top 10).

\section{POA Trauma Registry}

\begin{tabular}{|c|c|c|}
\hline Code & \# of Fractures & Description \\
\hline 42/A3 & 281 & $\begin{array}{l}\text { Tibia/Fibula-Diaphysis, Simple Fx Transverse } \\
\text { (<30 degrees) }\end{array}$ \\
\hline 06/A3 & 243 & Clavicle Diaphysis, Transverse \\
\hline 42/A2 & 229 & $\begin{array}{l}\text { Tibia/Fibula-Diaphysis, Simple Fx Oblique } \\
\text { ( } \geq 30 \text { degrees) }\end{array}$ \\
\hline 06/A2 & 226 & Clavicle Diaphysis, Oblique \\
\hline $32 / \mathrm{A} 3$ & 220 & $\begin{array}{l}\text { Femur-Diaphyseal, Simple Fx Transverse }(<3 \\
\text { degrees) }\end{array}$ \\
\hline 23/A2 & 181 & $\begin{array}{l}\text { Radius/Ulna-Distal, Extra-articular Fx of the } \\
\text { radius, simple and impacted }\end{array}$ \\
\hline 22/A3 & 147 & $\begin{array}{l}\text { Radius/Ulna- Diaphysis, Simple Fx of both } \\
\text { bones }\end{array}$ \\
\hline $32 / \mathrm{A} 2$ & 145 & $\begin{array}{l}\text { Femur- Diaphyseal, Simple Fx Oblique }(\geq 30 \\
\text { degrees) }\end{array}$ \\
\hline 25/B2 & 124 & Matecarpal Fractures, Diaphyseal \\
\hline 22/A2 & 116 & $\begin{array}{l}\text { Radius/Ulna- Diaphysis, Simple Fx of the } \\
\text { radius, ulna intact }\end{array}$ \\
\hline
\end{tabular}

Table 2. Summary of number of motor vehicles registered in 2008.

\begin{tabular}{lc}
\hline \multicolumn{1}{c}{ Type of Vehicles } & Percentage \\
\hline Motorcycle/Tricycle & $51 \%$ \\
Utility Vehicles & $27 \%$ \\
Cars & $13 \%$ \\
Trucks & $5 \%$ \\
Sports Utility Vehicles & $3 \%$ \\
Buses & $1 \%$ \\
Tractors & $1 \%$ \\
\hline (As of December 2008, there are 5,331,574 registered vehicles)
\end{tabular}

Because of the increasing popularity of motorcycles, there is a corresponding alarming increase in the number of fatalities and injuries. ${ }^{15}$ It is understandable that motorcycle riders are prone to injuries, because of the inherent disadvantage of their body being exposed while riding and the utter lack of enforcement for safety equipment such as motorcycle air bags and protective gear. ${ }^{16}$ This is characterized by increasing fatal and nonfatal road traffic accidents attributed to motorcycles as shown by the LTO database (2006-2008), which appears to be steadily rising through the year.

The LTO annual database record (2006-2008) ${ }^{6}$ showed that the top three (3) leading vehicles involved in fatal road accidents are as follows (in decreasing order): motorcycles, cars, and trucks. Among the leading causes of nonfatal accidents were motorcycles, cars, and jeepneys. There is an increasing trend in the number of motorcycles involved in nonfatal accidents.

Fifty percent $(50 \%)$ of both fatal and nonfatal motor vehicle accidents are due to vehicles hitting pedestrians. 
Likewise, the MMDA-MMRAS data from 2006-20087 shows that pedestrians account for $49.5 \%$ of fatalities for vehicular accidents, followed by drivers (31.5\%) and passengers (19\%). Noted however is a decreasing trend in pedestrian fatality, and the increasing trend in the fatality rate among drivers $(36.5 \%)$ in the last 3 years of data obtained.

It is notable from this study that motorcycle accidents occur at night until dawn, when conditions are poorer contributing to high fatality during nighttime. Driver factors such as overspeeding and driving under influence of alcohol are not discounted. It appears from previous studies (e.g., Montalban et al. $)^{17}$ and WHO data that alcohol in particular influences and increases vulnerability to vehicular crash and motorcycle accidents.

It is noteworthy that the victims, in almost all of the databases included in this study belong to age 21-35, which is the most productive age group. Hence, the implication of its adverse effect on the economy is easy to understand. ${ }^{18}$

It has been established in this study that injuries to the lower extremities are common in motorcycle accidents. This can be explained by the position of the victims while riding in motorcycle as their lower extremities are prone to getting pinned by the impacting vehicle, the road surface, and other fixed objects. ${ }^{19}$ The knee is understandably the most exposed compared to the other joints. Protective gear (like gloves, elbow and knee pads) are lamentably not required among Filipino motorcycle riders, except the use of helmets. ${ }^{20}$ The use of helmets is required by law, and probably accounts for the decreased number of head injuries among motorcycle riders.

The noted increase in incidence of brachial plexus injury in motorcycle accidents confirms the mechanism of injury in which the rider falls on one side of the head and ipsilateral shoulder, causing traction injuries to the cervical nerves ${ }^{10}$ but in general, only $2.4 \%$ of all musculoskeletal injuries can be traced to the spine.

\section{Summary and Recommendations}

In summary, there is an alarming increase in motorcycle accidents and a corresponding increase in fatalities. Furthermore, these accidents occur mainly among the young, 21-35 years of age.

As an offshoot of this study, the following are our recommendations:

1) To formulate a Motorcycle Accident Registry for a unified, comprehensive national database

2) To include Road Safety Education in elementary and high school curricula, to increase awareness of existing laws and effective early behavioral change

3) To provide for Motorcycle Lanes to protect both riders and pedestrians
4) To identify designated trauma centers to ensure rapid and proper care for road accident victims, and

5) To establish an effective referral network among hospitals for the efficient transport and care of these patients.

It is the advocacy of this author that a National Summit be held to address road safety, most especially to prevent or reduce the prevalence of motorcycle accidents, and to mitigate the attendant mortality and morbidity rates.

This summit can come up with recommendations so that Road Safety can be promoted and accidents can be prevented; in particular, motorcycle accidents can be abated as it is a growing national health concern in our country.

\section{References}

1. Department of Health Annual Report: Top Ten Leading Causes of Morbidity and Mortality 1970 - 2004.

2. Asian Development Bank - Association of Southeast Asian Nations Regional Road Safety Program Country Report CR 7: Philippines 2007.

3. Department of Orthopedics, Philippine General Hospital, Patient Registry, 2007-2008.

4. Department of Orthopedics, Philippine Orthopedic Center, Patient Registry, 2007-2008.

5. East Avenue Medical Center, Emergency Department Patient Records, 2006-2008.

6. Land Transportation Office Statistics Section Annual Reports, Department of Transportation and Communication, 2006 - 2008.

7. Metro Manila Development Authority (MMDA), Metro Manila Accident Reporting and Analysis System (MMARAS) Annual Report, 2005 - 2008.

8. Philippine Orthopedic Association (POA) Trauma Registry Annual Report, 2009.

9. Estrella EP, Dela Rosa T. Elbow reconstruction in brachial plexus injuries: A case series of 28 patients. Philipp J Surg Spec. 2009; 64(2):81-9.

10. Estrella EP. Functional outcome of nerve transfers for upper-type brachial plexus injuries. J Plast Reconstr Aesthet Surg. 2011; 64(8):100713.11.

11. Iamtrakul P, Tanaboriboon Y, Hokao K. Analysis of motorcycle accidents in developing countries: a case study of Khon Kaen, Thailand. J East Asia Soc Transport Stud. 2003; 5:147-62.

12. Libres GT, Galves ML, Cordero CJ. Analysis of relationship between driver characteristic and road accidents along Commonwealth Avenue. Undergraduate Research Program in Civil Engineering. 31 March 2008.

13. Department of Public Works and Highways (DPWH), Traffic Accident Reporting and Analysis System (TARAS) Annual Report, 2006 - 2007.

14. Sigua RG. Road Safety on Arterial Roads. UP National Center for Transportation Studies [Online]. 2003 [cited 2011 Dec]. Available from https:// ncts.upd.edu.ph/old/roadsafety/docs/3rd_rsarterialroads.pdf.

15. U.S. Department of Transportation, National Highway Traffic Safety Administration. Fatal Motorcycle Accidents, Technical Report. October 2001.

16. U.S. Department of Transportation, National Highway Traffic Safety Administration. Traffic Safety Facts 1999: Motorcycle.

17. Montalban AM, Osigan SA, Montalban Jr, AS. Motorcycle accident profile at San Juan De Dios Hospital. Philippine Journal of Orthopedics. 2008; 27(1):95-101.

18. de Leon MR, Sigua RG, Cal PC. Estimation of socio-economic cost of road traffic accidents in Metro Manila. J East Asia Soc Transport Stud. 2005; 6:3183-98.

19. U.S. Department of Transportation, National Highway Traffic Safety Administration. Lower-Extremity Injuries in Motorcycle Crashes. August 2008.

20. Safety Organization of the Philippines Incorporated (SOPI) Annual Report, 2006. 